\title{
TRIDESETLETNA VOJNA IN SLOVENCI
}

\author{
MARKO KerŠEVAN \\ Filozofska fakulteta Univerze v Ljubljani, Ljubljana (v pokoju) \\ marko.kersevan1@guest.arnes.si
}

Kočevar, Vanja, ur. 2020. Tridesetletna vojna in Slovenci: evropski konflikt in slovenski prostor v prvi polovici 17. stoletja. Ljubljana: Založba ZRC SAZU, 520 strani.

Ob 40o-letnici začetka tridesetletne vojne smo z nekaj zamude - na Slovenskem pogoste, če že ne kar običajne - dobili obsežno znanstveno monografijo, ki to vojno obravnava v zvezi s Slovenci oziroma slovenskim prostorom. Kot poudari njen urednik Vanja Kočevar, skuša delo s tem začeti odpravljati zamudo in veliko vrzel v slovenskem zgodovinopisju. Ne vem sicer od kod in od koga je prišla prva ideja/pobuda za to knjigo, gotovo pa je bil zgodovinar najmlajše generacije Vanja Kočevar najprimernejši, tako rekoč poklican, da jo kot avtor in urednik uspešno uresniči. Že tema njegovega diplomskega dela so bili Odmevi tridesetletne vojne na Kranjskem (Filozofska fakulteta UL, 2012), njegova doktorska disertacija pa je imela naslov Vojvodina Kranjska $v$ času Ferdinanda II. (1595-1637): politična zgodovina osrednje slovenske dežele (Filozofska fakulteta UL, 2016).

Dejstvo, ki ga ta monografija potrjuje in analizira, je, da tridesetletna vojna (1618-1648) s svojimi bitkami in spopadi sicer ni neposredno prizadela slovenskega prostora, toda ta in njegovi ljudje vendarle niso ostali zunaj odnosov in posledic te "prakatastrofe" in/ali »ene od osrednjih epopej evropskega zgodnjega novega veka« in da zato tudi ne more ostati zunaj slovenskega zgodovinopisja ter zanimanja in vedenja ljudi tega 
prostora sploh. Spričo tudi verskih vidikov, razlogov in posledic te vojne kot (tudi) katoliško-protestantskega soočenja in spopada še posebej ne more ostati zunaj zanimanja in vedenja »revije za vprašanje protestantizma« (kot smo že zapisali v »Besedi urednika« ob samem spominskem letu in objavi razprave Igorja Grdine Tridesetletna vojna v reviji (Stati inu obstati 29/2018, str. 13-57)).

\section{I.}

Že vpogled v naslove/tematike 18 prispevkov pretežno mlajših slovenskih zgodovinarjev pokaže zanimivo kompleksno sestavo monografije. Začenjajo in končujejo jo prispevki, ki predstavljajo znamenite dogodke in osebnosti te vojne $\mathrm{v}$ (srednje)evropskem merilu (praška defenestracija 1618, umor Wallensteina, likovni prikaz glavnih bitk in osebnosti v Valvasorjevi grafični zbirki). Sredino/jedro in največji del monografije tvorijo prispevki, ki so tako ali drugače usmerjeni v domače dogajanje, $\mathrm{v}$ slovenski prostor in njegove ljudi ter ki nenazadnje temelje na različnih arhivskih virih in drugih dokumentih iz tega prostora in o tem prostoru ter njegovih ljudeh iz tega obdobja: Arhiv Slovenije, Zgodovinski arhiv Ljubljana, Nadškofijski arhiv Ljubljana, Letopis Ljubljanskega kolegija Družbe Jezusove (1596-1691) pa seveda tudi Österreichisches Staatsarchiv in drugi tukajšnji ter tuji arhivi in zbirke knjig ter dokumentov.

Kot se za obletnice vojn spodobi, prispevki najprej obravnavajo vojaški vidik, za tem političnega in posredno ekonomskega (ko govore o predvsem finančni politiki deželnih stanov) ter verskega (posebej ko raziskujejo verske vidike v odnosih med ljudmi v tem času na primeru Maribora in Ptuja). Ponujeni sta lokalno usmerjeni raziskavi in posredno primerjavi dogajanja v Ljubljani in Prekmurju. Posamezni prispevki raziskujejo dogajanje na področju pismenosti (slovenskih rokopisov 17. stoletja), glasbe in likovnih upodobitev. S posebnimi prispevki je ponujen vpogled v različne domače arhivske vire in sočasne oziroma zgodnje »domače « obravnave ter prikaze 3o-letne vojne (v dokumente nadškofijskega arhiva v Ljubljani, ki govore o vojni, v spise domačih avtorjev 
iz druge polovice 17. stoletja, kot sta Schönleben in Pelzhoffer). Skoraj vsi prispevki tako ali drugače tudi sami vključujejo osnovna vedenja o tridesetletni vojni, čeprav obravnavajo specifična vprašanja in vidike $\mathrm{v}$ našem prostoru in se tako rekoč vsi opirajo predvsem na svoje neposredno novo raziskovanje domačih arhivov ter drugih virov. Slednje je gotovo samo po sebi pomemben prispevek in odlika sedanje najmlajše generacije slovenskih zgodovinarjev, zbranih ob tej knjigi. Hkrati pa to poudarjeno opiranje, včasih že kar omejevanje, na vire/arhive iz našega prostora lahko privede tudi do neuravnotežene podobe dogajanja ali ljudi: ne gre prezreti, da so bili pri nastajanju in kasnejšem hranjenju/ selekciji (dokumentov, zapisnikov, spominov, tudi slik) pri nas takrat in kasneje na delu predvsem katoliške roke, ki so hote ali nehote vendarle po svoje pisale, beležile, selekcionirale, hranile ali zametavale (na nekaj primerov tega bomo opozorili).

Vse skupaj je pospremljeno s krajšim uvodnim prispevkom o 30-letni vojni, njenih dilemah in naukih. Prispevke je mogoče brati tudi posebej in posamično. Ta ugotovitev naj bo razumljena kot izraz priznanja njihovi kvaliteti in izziv/poziv k njihovemu branju!

\section{II.}

Pa vendar tudi na tem mestu nekoliko selektivno preglejmo posamezne prispevke in zabeležimo posamezne (po)misli, ki so se ob branju porodile piscu tega pregleda.

Uvodno besedilo pod naslovom Tridesetletna vojna s tridesetletno senco je prispeval Aleš Maver. Čeprav kot zgodovinar ni specialist za obdobje in problematiko 17. stoletja, je napisal zelo dober, mestoma prav pronicljiv in tudi za občutljivo problematiko verskih vidikov te vojne spodoben uvod, na ravni in $\mathrm{v}$ duhu presoj, ki prevladujejo $\mathrm{v}$ sodobnem zgodovinopisju. K temu je gotovo prispevala tudi opora na dobro najnovejšo strokovno literaturo, na primer na dela Georga Schmidta, učenca zdaj že pokojnega tübingenskega profesorja in zgodovinarja Volkerja Pressa, ki smo ga nekateri starejši lahko osebno srečali tudi v Ljubljani 
(in kasneje v Tübingenu) ob simpoziju »Slovenci v evropski reformaciji« (Filozofska fakulteta UL, 1983), kjer je odločno in meritorno poudaril Trubarjevo samostojnost in pogum $v$ zapletenih razmerah njegovega življenjskega okolja ter časa.

Žal pa se avtor ni povsem odlepil od značilnih prijemov tradicionalne katoliške apologetike pri soočenju $\mathrm{z}$ občutljivo problematiko, ko je uporabljala evfemizme, (ne)ustrezno selekcioniranje dejstev in relativiziranje sodb. Taki prijemi seveda niso le značilnost ali celo monopol katoliške strani, nesporno pa se je prav katoliška apologetika pri tem v svoji dolgi, najdaljši tradiciji najbolj izmojstrila. Pri avtorju jo lahko opazimo v dveh primerih. Znano uničenje Magdeburga in pokol prebivalcev s strani katoliško-cesarskih zvede na "slovito obleganje Magdeburga«, ki se je "zaključilo s katoliško 'zmago', a je ob njej izbruhnil požar, ki je uničil prej cvetočo metropolo in število mestnega prebivalstva s približno 25.00o zmanjšal na manj kot tisoč« (str. 11). In to je vse. Avtor opozarja, da je protestantska publicistika zlasti v 19. stoletju Gustava Adolfa povzdignila $\mathrm{v}$ "protestantskega leva« in nasproti njemu postavila negativno podobo katoliškega vojskovodje Tillyja. Temu nasproti upravičeno opozarja na večjo "prizemljenost in kompleksnost« njunih podob v sodobni historiografiji. Toda ob tem ne spomni, da je tudi katoliška stran povzdigovala in loščila svoje junake, na primer cesarja Ferdinanda II. kot »čistega« ali celo »svetega«, medtem ko ga sodobna historiografija ocenjuje bolj prizemljeno in kompleksneje (Dante pa bi ga - po moji enostranski presoji seveda - verjetno umestil v enega globljih krogov pekla).

Prvi prispevek, kot rečeno, raziskuje in opisuje znano praško defenestracijo in njene "žrtve«. Lahko bi rekli, da članek pokaže zadrego zdaj čedalje bolj razširjenega tipa novejšega zgodovinopisja, ki na osnovi temeljite raziskave virov in dokumentov izoblikuje podrobno pripoved/ zgodbo o nekem konkretnem dogajanju in ljudeh. Ko/če jo berejo nestrokovnjaki, taka pripoved izvisi v zraku, ker/če ti ne poznajo dovolj širšega okvira in temeljev dogodka. Avtor je vedenje in pojasnila o širšem zgodovinskem dogajanju in osebnostih dodal v obsežnih opombah. Tu pa se srečujemo z dilemo: glede na to, da so sodobni, zdaj bolj ali manj po anglosaški »šoli« izobraženi bralci zgodovinsko čedalje bolj nevedni 
(v primerjavi s starimi, »evropsko« šolanimi generacijami), bi to zahtevalo čedalje več opomb in pojasnil; po drugi strani pa so splošna in tudi konkretna vedenja danes prek interneta lahko in hitro dostopna vsakomur, tudi bralcem takih tekstov. Kaj torej storiti in kako pisati?

"Domače« prispevke začenja članek Tomaža Lazarja o orožarski materialni zapuščini 30 -letne vojne pri nas. Na našem prostoru v tem času sicer ni bilo bitk, orožje iz časa teh spopadov pa se je kljub temu ohranilo tudi pri nas, čeprav ga je relativno malo, saj je bila za slovenske dežele takrat glavna in zaresna bojna črta meja z Otomanskim imperijem. Orožje se je pri nas ohranilo, ker so ga uporabljali tudi ljudje iz naših krajev na poteh in pohodih po Evropi ali ker so ga zapustili vojaki/najemniki, ki so v tistem času prišli k nam.

Naslednja dva članka pišeta o vojakih/najemnikih iz časa 3o-letne voj$n e$, posebej seveda o vojakih najemnikih s Kranjske in na Kranjskem: članek Mihe Šimca širše, raziskava Janeza Weissa pa se posveča vojaški karieri metliških plemičev Kanižarjev in vojakom, ki so jim poveljevali. Oba dobro dokumentirana članka sta zelo zanimivo branje. Prvi članek zajame v obravnavo tudi vojake cesarskega polka Ferrari, ki/ko je bil nastanjen $v$ Ljubljani in se je zaradi tatvin ter vznemirjanja prebivalcev zapletel v krvav spopad z Ljubljančani; poroča tudi o novačenju vojakov s strani polka Gonzaga v sami Ljubljani leta 1643, ko je cesarskim spričo porazov in izgub tekla voda $v$ grlo, pa so vsepovsod iskali rezerve: v Ljubljani naj bi jim uspelo nabrati okrog 250 vojakov. Avtor je zbral in objavil podatke o nekaterih osebah s Kranjskega, ki so zabeležene kot udeleženci v vojnah, posebej ker/če so dosegli častniške čine. Tako srečamo imena (in usode) barona Paradejserja, Wolfa, enega od Auerspergov ter številnih drugih, ki so služili cesarju, tudi konkretno Wallensteinu. Srečamo imeni dveh bratov iz Črnuč, od katerih je bil eden v cesarski, drugi pa je padel v švedski službi ob Bodenskem jezeru. V člankih so omenjeni tudi plemiči (Črnomaljski, koroški Khevenhüllerji), ki so se bojevali na protestantski strani; toda v uporabljenih naših ali drugih katoliških virih so zabeležena le imena s katoliške strani (o tem kasneje).

Posebej zanimiva je raziskava in razprava Janeza Weissa o Kanižarjih, ki je na nek način nadaljevanje in konkretizacija prejšnje, ko se osredo- 
toči na poti in usode metliške plemiške rodbine Kanižarjev (po poreklu iz Slavonije), posebej na neposrednega in posrednega udeleženca bojev v 3o-letni vojni, Mihaela Kanižarja. O njem piše že Valvasor, avtor pa na osnovi raziskave (novih) virov razširi in tudi kritično dopolni dosedanje (Valvasorjevo) pisanje o njem. Študija je posebej zanimiva za branje, ker na osnovi virov spregovori o znameniti hrvaški lahki konjenici (»Croaten«) v tridesetletni vojni in mimo nje. (V njenih vrstah sicer niso bili le Hrvati, so pa prevladovali.) Bili so (in ostali) dvomljivega slovesa: hrabri, odločni, včasih v spopadih celo odločilni, hkrati pa nedisciplinirani, nezanesljivi, »sloveči« tudi po ropanju in nasilju nad civilnim prebivalstvom. Mihael Kanižar je poveljeval takemu oddelku in preko njega pripelje avtor $v$ študijo tudi bitke, v katerih je sodeloval. Weiss omenja tudi nekega Lambergerja, Kranjca in protestanta, v vojski katoliškega bavarskega vojskovodje (str. 167).

$\mathrm{S}$ prispevkom Andreja Hozjana Vojna in (občasni) mir: Prekmurje (s Porabjem) v luči tridesetletne vojne se srečamo $\mathrm{z}$ dinamiko dogajanja $v$ trikotu med Habsburžani, protihabsburškim madžarskim/sedmograškim plemstvom in osmanskim imperijem. Zvemo tudi, da kot žrtev umora/ atentata v tem času ni padel le Wallenstein, ampak že prej (1626) tudi Jurij Zrinjski (zastrupljen na Wallensteinov ukaz) in z Zrinjskimi povezani član rodbine Rima-Seči (Szecsi) Jurij, protihabsburški protestant (umorili so ga s kraljeve/katoliške strani najeti morilci; njegov najmlajši sin Tomaž je kasneje prestopil v katolištvo). Če članek o Prekmurju sledi razmerjem in usodam (naj)višjih slojev, članek Irene Žmuc Ljubljana na robu opisuje doživljanje bede (»umorov, požigov in ropov«) med najrevnejšim mestnim prebivalstvom, posebej med številnimi domačimi in tujimi berači.

Urednik zbornika Vanja Kočevar se je tokrat posvetil osrednji politični ustanovi tega prostora, deželnemu zboru kranjskih deželnih stanov, in njegovi osrednji dejavnosti, povezani s 30-letno vojno: ta pa je bila, kot kažejo preučeni regesti in zapisniki njegovih zasedanj, zagotavljanje stalno novih in novih finančnih sredstev neposredno za vladarjevo blagajno ali pa zagotavljanje nastanitve, oskrbe ali popolnitve/novačenja posameznih vojaških enot. Kranjska ni pošiljala posebnih enot 
na bojišča, je pa delno financirala omenjene hrvaške oddelke. Izredne vojne dajatve so morali plačevati vsi posamezniki (in vse ustanove): od kajžarjev in gostačev (po nekaj krajcarjev), služinčadi (po nekaj šilingov) do trgovcev in gospode (po več deset goldinarjev).

Vincenc Rajšp umešča slovensko reformacijo $v$ širši evropski prostor. Pridružuje se tistim, ki uporabljajo izraz (katoliška) reformacija tudi za katoliške tridentinske in druge reforme ter dokumentira, kako so o »brezbožni papinski reformaciji« govorili tudi protestanti tistega časa (str. 294). (O uporabi izraza reformacija piše v številki 21-22/2015 naše revije Emidio Campi.) Gotovo je pomembno in potrebno Rajšpovo opozorilo na poseben položaj v habsburških dednih deželah (kot so bile Kranjska, Štajerska, Koroška) v primerjavi z deželami drugih katoliških ali protestantskih vladarjev znotraj Svetega nemškega cesarstva. Ne le da je bil tu katoliški cesar tudi katoliški deželni knez; ni bilo niti samostojnih državnih mest (kot na primer na Bavarskem, s sicer tudi katoliškim deželnim vladarjem). Notranja Avstrija je bila področje koncentrirane (pre)moči katoliškega habsburškega vladarja.

Žiga Oman ob uporabi arhivskih in drugih virov iz Maribora in Ptuja razpre doslej zanemarjen - ne le pri nas - vidik obravnave problematike reformacije in protireformacije: vprašanje ljudske religioznosti, vprašanje dejanskega verovanja, verskega opredeljevanja in prakticiranja $\mathrm{v}$ konkretnem življenjskem okolju in obdobju. Dokumentirano in pronicljivo opozori (spodbujen tudi z novejšo tujo strokovno literaturo) na razliko med uradno cerkveno in oblastno versko politiko, njunimi zapovedmi in prepovedmi ter dejanskim uresničevanjem te politike $\mathrm{v}$ konkretnem ( $\mathrm{v}$ tem primeru mestnem) okolju z njegovimi medosebnimi, socialnimi, sorodstvenimi, poklicnimi razlikami in prepletanji, ki pogojujejo pragmatizem pri njenem (ne)uresničevanju. Tako načrtovana konfesionalizacija kot uradno »izpogajani« verski mir sta bila pri uresničevanju v veliki meri odvisna od kompleksnih razmer in razmerij v konkretnih lokalnih skupnostih: te so lahko ohranjale med- ali nadkonfesionalni sinkretizem, omogočale prikrivanje "zaresnih" verskih opredelitev ali njihovo marginalizacijo, lahko pa so tudi utrjevale ali zaostrovale konfesionalne razlike. Avtor zanimivo opozarja na vztra- 
janje (prikritih) protestantskih opredelitev in ravnanj med meščanskimi in plemiškimi ženami in ga povezuje $z$ družbenim položajem žensk. Zanimivo je tudi zabeleženo nihanje v (ne)samozavesti takrat že prikritih protestantov oziroma lažnih katoličanov ob švedskih zmagah v vojni.

Matija Ogrin motri obdobje 30-letne vojne $\mathrm{z}$ vidika poznanih ocen, da je to (in kasnejše 17. stoletje) obdobje zastoja slovenske knjige in tiska. Zaradi številnih rokopisov v slovenskem jeziku prav iz tega časa pa bi bilo po njegovem to obdobje ravno tako smiselno označiti kot »dobo slovenskih rokopisov«. Ugotavlja namreč, da je katoliška prenova v času baroka povečala potrebo po pisani slovenski besedi v cerkvenem delovanju in verskem življenju. Rokopisi so bili odgovor na to potrebo. Pokaže, da so rokopisna besedila verskih pesmi črpala tudi iz starejših, tiskanih protestantskih pesmaric, kot so se te po drugi strani opirale na starejšo ustno tradicijo »katoliških « ljudskih pesmi in jih hkrati »čistile« »zmot« (Trubar) oziroma »pretiravanj« (Ogrin) (na primer opevanje Marije kot »stvari, ki je rodila stvarnika«); tako očiščena je bila pesem o Mariji prevzeta tudi v katoliškem rokopisu. Avtor razlaga, da je usahnitev verskega tiska v slovenskem jeziku posledica finančnih težav obdobja vojne, ob dejstvu, da katoliško plemstvo slovenskega tiska ni bilo pripravljeno tako podpreti, kot ga je prej protestantsko. To ni brez osnove, toda ne gre prezreti, da sta temu botrovala tudi bistveno drugačen status ljudskega jezika in drugačno razmerje med duhovnikom ter navadnimi verniki v katolištvu in protestantizmu. Beseda Svetega pisma in "pridiga po Božji besedi« (sola scriptura) sta po Luthru edina pot (do) vere, ta pa edina pot (do) odrešenja (sola fide): kot taka mora biti enako dostopna/ponujena vsem ljudem v njihovem jeziku in kot taka je navzoča v pridigi kot jedru protestantskega bogoslužja. V (takratnem) katolištvu je bilo zakramentalno jedro bogoslužja izključno v rokah duhovnika in njegovih (takrat) latinskih besed. Ljudski jezik je bil navzoč in potreben zgolj v sekundarnem, perifernem delu: v pridigi kot vzgojnem sredstvu, v cerkveni pesmi, v ljudskih priprošnjah ali slavilnih pesmih, pri spovedi in zaobljubah, procesijah in spektaklih. Zapisi v ljudskem jeziku so bili predvsem pomožno sredstvo duhovništvu, da je lahko vo- 
dilo, usmerjalo in nadzorovalo ljudsko pobožnost: za to pa so za silo zadoščali rokopisi.

Tri besedila nudijo vpogled v dogajanje časa vojne skozi »oči« (skoraj) sočasnih virov in dokumentov. Julijana Visočnik prikaže (in nakaže), kaj nudijo dokumenti nadškofijskega arhiva v Ljubljani (NSAL). V večini gre za prepise poročil o bitkah in osebah iz širšega evropskega prostora, ki so takrat krožila; malo je takih, ki se nanašajo na dogajanje pri nas. Tako je na primer pismo/naročilo cesarskega sveta ljubljanskemu ško$\mathrm{fu}$, naj po porazu cesarskih pri Leipzigu leta 1642 poskrbi za procesije, molitve in ustrezne pridige (361). Zanimiv in zgovoren je zgodovinopisni in literarni odmev 30-letne vojne v obsežnem nemško in latinsko pisanem opusu Janeza Ludvika Schönlebna (rojenega v letu začetka vojne 1618), ki ga je raziskala Monika Deželak Trojar. Schönleben niza in opisuje tako rekoč samo cesarsko-katoliške zmage, poraze obide. Tako zabeleži zmagovito zavzetje Heidelberga in omeni, da je slavna Bibliotheca Palatina končala (kot vojni plen in darilo papežu) v Vatikanu (in spomnimo, z njo tudi izvod Trubarjeve Cerkovne ordninge, najden tam leta 1973). Zmago v bitki pri Lützenu leta 1632, v kateri je padel švedski kralj Gustav Adolf (in cesarski poveljnik Pappenheim), v tej maniri pripiše cesarju Ferdinandu II., čeprav velja v zgodovinopisju za sicer »Pirovo zmago « Švedov. Pri tem sploh ne omenja Wallensteina, ki je bil na cesarski strani vendarle najzaslužnejši za kolikor toliko ugoden izid spopada. Ferdinand II. naj bi sploh živel in umrl nadvse pobožno, še več, zapiše, da »Ferdinandus sanctus est (str. 410). Schönleben se pokaže kot pravi slavilec Avstrije in Habsburžanov. Ne pozabi posebej izpostaviti, da so bili veliki častilci Marije, kot na primer vojskovodja Leopold Wilhelm, mlajši brat cesarja Ferdinanda III., ki ga kljub porazom hkrati poimenuje »Avstrijski Mars«, »Avstrijski Herkul«. S poudarjanjem avstrijske in habsburške katoliške pobožnosti je hote ali nehote prispeval k pojmovanju 30-letne vojne kot (»verske«) vojne, ki jo je posebej v začetkih poganjalo tudi katoliško zelotstvo Ferdinanda II. in strah pred njim.

Pojmovanje te vojne tudi kot verske vojne - kjer da je na habsburški strani vseskozi bila Marijina in Božja pomoč ali vsaj zaupanje vanjo odseva tudi v pisanju kranjskega pravnika Franza Alberta Pelzhofferja (1643-1710) in njegove žene, baronice Paradeiser. Pelzhofferjeve poglede 
na politično zgodovino, 3o-letno vojno in različne mirovne sporazume iz leta 1710 v knjigi predstavi Filip Draženović.

Knjigo in sliko časa popestrita prispevka o glasbi v ljubljanski (in gornjegrajski) stolnici $\mathrm{v}$ času škofa Hrena (Klemen Grabnar) in plesni glasbi Isaaca Poscha (rojen v Kremsu 1591, umrl 1623), morda potomca protestantske ljubljanske trgovske družine Posch, vsekakor pa protestantskega verskega »esulanta«, ki je v letih 1617-1622 deloval tudi na Kranjskem in Koroškem, se tu tudi poročil in umrl. Kot strokovnjak za orgle je delal za škofa Hrena, svoji glasbeni deli Veselo glasbeno slavje (Musikalische Ehrenfreundt, 1618) in Veseli glasbeni banket (Musicalische Tafelfreundt, 1620) pa je natisnil v svobodnih cesarskih mestih Regensburgu in Nürnbergu ter ju posvetil koroškim in kranjskim deželnim stanovom. Avtorica prispevka Metoda Kokole je o njem napisala tudi monografijo, ki je izšla leta 1999 pri ZRC SAZU in 2009 pri znani založbi Peter Lang.

Monografijo zaključujejo likovne upodobitve 3o-letne vojne in njenih protagonistov v Valvasorjevi grafični zbirki (pripravil Gašper Cerkovnik) in posebej upodobitev »izvensodne usmrtitve«, uboja Albrechta Wallensteina in njegovih privržencev leta 1634 (Polona Vidmar). Zaključna prispevka tako monografijo vrneta h ključnemu (srednje)evropskemu dogajanju, s katerim je s praško defenestracijo leta 1618 tudi začela. Lahko rečemo, da jo vrneta na izjemno slikovit in zanimiv način: $\mathrm{z}$ likovnimi upodobitvami, ki so nastale že v času vojne, in preko prikaza umora Wallensteina v okviru opisa enega glavnih zarotnikov, škotskega plemiča Valterja Leslieja oziroma njegovega glavnega dejanja. Po koncu vojne je od cesarja bogato nagrajeni Leslie nadaljeval vojaško in diplomatsko kariero na Balkanu, bil odposlanec $\mathrm{k}$ sultanu Mehmedu IV. in leta 1656 kupil gospostvo Gornji Ptuj.

\section{III.}

Prelet posameznih prispevkov in zabeleženje vtisov in pomisli ob njih (posebej tistih, ki so relevantni za "vprašanja protestantizma« v 
obravnavanih prostorih in časih) lahko sklenemo - celo moramo - z oceno, da so urednik in avtorji posameznih prispevkov opravili odlično in pomembno delo: dobili smo kompleksno, večplastno, zanimivo in berljivo delo, s skrbno dokumentiranimi prispevki, tudi z na novo ali prvič preiskanimi domačimi arhivskimi in drugimi viri. V knjigi so objavljeni in uspešno združeni prispevki, ki so po večini nastali v okviru različnih raziskovalnih projektov zadnjih let in ki bi sicer ostali dostopni le specializiranim raziskovalcem.

Če odmislimo posamezne kritične pripombe in manjše potrebne popravke, ki se jim ne more izogniti nobeno tako obsežno delo, se ob taki oceni kritičen pogled neizogibno usmeri k vprašanju, kaj v delu eventualno manjka, kaj pogrešamo in kaj zato kliče po nadaljnjih raziskavah ter objavah.

Pod naslovom Tridesetletna vojna in Slovenci ter podnaslovom Evropski konflikt in slovenski prostor v prvi polovici 17. stoletja pogrešamo obravnavo glavnega dogodka tega časa na Slovenskem, povezanega (tudi) s potekom 30-letne vojne: izselitve (ali spreobrnitve) velikega dela protestantskega plemstva (kot neposredne posledice odloka Ferdinanda II. iz leta 1628, na višku njegovih vojnih uspehov, preden so v spopade posegli Švedi). Urednik zbornika je pri tem po eni strani »opravičen«, saj je temu dogajanju v svojih raziskavah in objavah pri nas v zadnjem času prav on posvetil največ pozornosti (tako tudi v predavanju/razpravi Ferdinand II. na čelu protireformacije: plemstvo in konfesionalne razmere na Kranjskem v prvi tretjini 17. stoletja v reviji Stati inu obstati 2122/2015, str. 180-233). Toda če drugega ne, bi bilo potrebno odsotnost tega v monografiji nujno na nek način pojasniti in utemeljiti vsaj v splošnem uvodu. Za tako opravičilo/utemeljitev ne morejo veljati »Slovenci« v naslovu, saj podnaslov smiselno izpostavi »slovenski prostor« (in prispevki smiselno obravnavajo protagoniste dogajanj v tem prostoru, ne glede na njihovo etnično/jezikovno poreklo in opredelitev)

$\mathrm{S}$ tem mankom je povezan še drugi: obravnava protestantskih plemiških (in meščanskih) eksulantov iz tega prostora in posebej njihovega delovanja v času in dogajanju 3o-letne vojne, nenazadnje tistih, ki so aktivno sodelovali na švedski strani. Dejstvo, da je šlo v tem primeru za 
dogajanje/delovanje zunaj slovenskega prostora, ne more biti zadosten razlog za neobravnavo, saj so v knjigi smiselno in upravičeno deležni pozornosti cesarsko-katoliški poveljniki in vojaki, tudi če niso bili Slovenci in so bili le posredno povezani s slovenskim prostorom (kot "Croaten « v cesarski vojski). Mnogo plemiških protestantskih beguncev je sodelovalo v vojni na švedski strani in nekateri med njimi so med vojno in po njej naredili uspešno kariero v švedski službi. Nekateri so tudi padli v bojih, kot polbrat in dva sinova Paula Khevenhüllerja, ki je bil do leta 1629 na čelu koroških deželnih stanov, v vojni pa je za švedskega kralja financiral regiment konjenikov in mu tudi poveljeval ter bil že leta 1645 sprejet $\mathrm{v}$ vrste najvišjega švedskega plemstva. Zaradi teh zaslug so Švedi zahtevali in dosegli, da je v ustrezen paragraf vestfalske/osnabrüške mirovne pogodbe prišla zahteva po povrnitvi zaplenjenih rodbinskih posestev na Koroškem. Švedi so si tudi sicer na mirovnih pogajanjih prizadevali za povrnitev pravic avstrijskega protestantskega plemstva, toda Habsburžani pri svojih dednih deželah (in Češki) niso popustili (in tudi omenjeni paragraf ni bil uresničen, kljub dolgotrajnim sodnim postopkom). Tudi potomci izseljene ljubljanske meščanske družine Snoilsky/Znojilškov so pustili pomembne sledove. Kot lahko preberemo že v Enciklopediji Slovenije in kot je tam pisal pokojni Janez Stanonik, je bil eden od njih pisar švedskega vojnega kabineta, kot tak je sodeloval pri pripravah mirovne konference v Osnabrücku in bil po vojni švedski diplomat ter odpravnik poslov pri državnem zboru v Regensburgu. Skratka, več kot dovolj za kaj več kot zgolj posamezne bežne omembe v obravnavani monografiji. Zgled in spodbuda bi bilo lahko delo Petra Thalerja »Protestanti habsburških dednih dežel in protestantska velesila Švedska v 17. stoletju. « Razpravo pozna in jo navaja tudi urednik monografije v omenjenem članku v Stati inu obstati 21-22/2015 (iz nje so tudi zgornji podatki iz švedskih virov).

1 Peter Thaler, »Erbländische Protestanten und die protestantische Großmacht Schweden im 17. Jahrhundert, " v Glaubwürdig bleiben: 500 Jahre protestantisches Abenteuer; Wissenschaftlicher Begleitband zur Kärntner Landesausstellung 2011 in Fresach, ur. Wilhelm Wadl (Celovec: Verlag des Geschichstvereines für Kärnten, 2011), 261-83. 
Mimogrede: ko govorimo o »slovenskem prostoru« $\mathrm{v}$ zgodovini, se ne gre omejevati na tedanjo Kranjsko niti na sedanje državno ozemlje Slovenije: niti ni bila Kranjska takrat v celoti jezikovnoetnično slovenska (čeprav je v veliki večini bila), niti nista bili tedanja Štajerska in Koroška v celoti neslovenski (čeprav sta v večini bili).

Drugo novejše delo, ki dokumentirano sledi usodi avstrijskih esulantov sploh, je obsežna študija (skoraj 800 strani) Wernerja Wilhelma Schnabla. ${ }^{2}$

Še najbolj utemeljen in najverjetnejši razlog za umanjkanje te problematike je dejstvo, da so se avtorji monografije zavestno posebej usmerili $\mathrm{k}$ doslej premalo raziskanim arhivskim in drugim virom na sedanjem slovenskem državnem prostoru. To, kar je po eni strani gotovo odlika in zasluga avtorjev, pa je po drugi strani, kot vse kaže, tudi izvor »enostranskosti« rezultatov raziskovanja. Kot smo že rekli: vire, dokumente, zapisnike, poročila, spomine in preglede pišejo, (i)zbirajo, ohranjajo (ali uničujejo), delajo (ne)dostopne v največji meri zmagovalci. ${ }^{3}$ In ti so bili v našem prostoru pač cesarski/habsburški/katoliški, in ti so tako ali drugače skrbeli predvsem za svoje, za »naše«. Že zato bi bilo dobro, če bi avtorji, ki delajo na (takih) arhivskih dokumentih, se opirajo ali celo omejujejo predvsem nanje, to tudi (na)povedali in ne ostajali pri zava-

2 Werner Wihelm Schnabel, Österreichische Exulanten in Oberdeutschen Reichsstädten: Zur Migration von Führungsschichten im 17. Jahrhundert (München: C.H. Beck, 1992).

3 Drastičen primer iz naše (proti)reformacijske zgodovine je "neznana usoda Petra Kupljenika«. Domači zgodovinarji so na osnovi (pomanjkanja) domačih virov vseskozi zatrjevali, da se o Kupljeniku po letu 1590 »nič ne ve«. Šele italijanski raziskovalci (Silvano Cavazza, Sergio Bonazza) in Johann Rainer iz Gradca so v Rimu ne le odkrili dokumente o njegovi usodi (smrti na grmadi na Campo dei Fiori 20. maja 1595), ampak našli tudi pričevanja o tem, da se je na Kranjskem o njegovi smrti takrat govorilo in da so »luterani tega heretika povzdigovali kot mučenca" (kot piše oglejski inkvizitor Benni v pismu 1. julija 1595). O tem (z bibliografskimi podatki) v moji knjigi Protestanti(sti)ka (Ljubljana: Cankarjeva založba, 2012), v poglavju »Pa vendar: Peter Kupljenik in slovenski zgodovinski spomin«. V Stati inu obstati 13-14/2011 glej prispevek: Sergio Bonazza, »Novi arhivski dokumenti o Petru Kupljeniku«: 292-96. 
jajočih splošnih naslovih. (Pri tem ne mislim na avtorje in urednika te monografije, ki so na to na različnih mestih dovolj opozorili!)

A še enkrat: urednik in avtorji zaslužijo pohvalo in zahvalo za to, kar so v tem okviru naredili in ponudili v branje; $\operatorname{kar}(\mathrm{še})$ niso, naj bo izziv in naloga za nadaljnje raziskave (in njihovo financiranje). 